\title{
Antimicrobial nanostructured starch based films for packaging
}

\author{
Ana S. Abreu ${ }^{\mathrm{a}, *}$, M. Oliveira ${ }^{\mathrm{a}}$, Arsénio de Sáa ${ }^{\mathrm{a}}$, Rui M. Rodrigues ${ }^{\mathrm{b}}$, Miguel A. Cerqueira ${ }^{\mathrm{b}}$, \\ António A. Vicente ${ }^{\mathrm{b}}$, A.V. Machado ${ }^{\mathrm{a}}$ \\ a Institute of Polymers and Composites (IPC) and Institute of Nanostructures, Nanomodelling and Nanofabrication (I3N), University of Minho, \\ Campus de Azurém, 4800-058 Guimarães, Portugal \\ b Centre of Biological Engineering (CEB), University of Minho, Campus de Gualtar, 4710-057 Braga, Portugal
}

\section{A R T I C L E I N F O}

\section{Article history:}

Received 9 December 2014

Received in revised form 5 March 2015

Accepted 8 April 2015

Available online 22 April 2015

\section{Keywords:}

Starch

Antimicrobial activity

Silver nanoparticles

Organoclay

Nanostructured films

Food packaging

\begin{abstract}
A B S T R A C T
Montmorillonite modified with a quaternary ammonium salt C30B/starch nanocomposite (C30B/ST-NC), silver nanoparticles/starch nanocomposite (Ag-NPs/ST-NC) and both silver nanoparticles/C30B/starch nanocomposites (Ag-NPs/C30B/ST-NC) films were produced. The nanoclay (C30B) was dispersed in a starch solution using an ultrasonic probe. Different concentrations of Ag-NPs (0.3, 0.5, 0.8 and $1.0 \mathrm{mM})$ were synthesized directly in starch and in clay/starch solutions via chemical reduction method. Dispersion of C30B silicate layers and Ag-NPs in ST films characterized by X-ray and scanning electron microscopy showed that the presence of Ag-NPs enhanced clay dispersion. Color and opacity measurements, barrier properties (water vapor and oxygen permeabilities), dynamic mechanical analysis and contact angle were evaluated and related with the incorporation of C30B and Ag-NPs. Films presented antimicrobial activity against Staphylococcus aureus, Escherichia coli and Candida albicans without significant differences between Ag-NPs concentrations. The migration of components from the nanostructured starch films, assessed by food contact tests, was minor and under the legal limits. These results indicated that the starch films incorporated with $\mathrm{C} 30 \mathrm{~B}$ and Ag-NPs have potential to be used as packaging nanostructured material.
\end{abstract}

(c) 2015 Elsevier Ltd. All rights reserved.

\section{Introduction}

The development of nanostructured materials, revealed a promising advance in nanotechnology, materials and life sciences (Ojijo \& Sinha Ray, 2013). They can be composed by a natural polymer matrix and organic/inorganic reinforcement with at least one dimension on the nanometer scale (Darder, Aranda, \& Ruiz-Hitzky, 2007). Moreover, these materials show the extraordinary advantages of biocompatibility and biodegradability in medical, drug release, packaging and agricultural applications (Mangiacapra, Gorrasi, Sorrentino, \& Vittoria, 2006; Reddy, Vivekanandhan, Misra, Bhatia, \& Mohanty, 2013; Sorrentino, Gorrasi, \& Vittoria, 2007; Sozer \& Kokini, 2009).

Among natural polymers, starch is one of the most promising biocompatible and biodegradable material, which has received attention due to its strong advantages, such as, low cost, wide availability from many plants and total compostability without the formation of toxic residues (Mathew \& Dufresne, 2002). In their native form, starches are organized into semicrystalline granules,

\footnotetext{
* Corresponding author. Tel.: +351253 510320; fax: +351253510339.

E-mail address: anasofiaabreu@dep.uminho.pt (A.S. Abreu).
}

presenting poor mechanical properties and high water affinity. The addition of nanofillers aims to improve some of these properties. In contrast, the macromolecular chains of this biopolymer possess a large number of hydroxyl groups, which is excellent for metal complexation. The hydroxyl groups provide active sites for metal ions enabling a good control of size, shape and dispersion of the formed metallic nanoparticles (Raveendran, Fu, \& Wallen, 2006). The development of nanostructured materials with metallic nanoparticles, such as silver nanoparticles (Ag-NPs), is highly useful to minimize the growth of contaminants by microorganisms. Therefore, there is a raising interest in developing bio-based polymers with antimicrobial activity. Silver nanoparticles (Ag-NPs) are known to have inhibitory and antimicrobial properties and low toxicity, receiving special attention by the industry. Ag-NPs can also be employed as absorbent pads in food packaging to absorb moisture and fluids exuded from meat and fish, keeping the products looking fresh and creating an aesthetically attractive packaging (Cho, Park, Osaka, \& Park, 2005; Duncan, 2011). The Ag-NPs interactions with microorganisms are dependent on size and shape of the nanoparticles but the inhibition mechanism of Ag-NPs remains unclear (Pal, Tak, \& Song, 2007).

The simplest and most direct route to metal nanoparticles synthesis is in situ generation inside a solid polymer film, which 
involves the preparation of thin polymeric film containing the metal precursor, which will generate the nanoparticles within the polymer matrix through a variety of chemical and physical methods (Ramesh, Porel, \& Radhakrishnan, 2009).

Nanoclay have been largely used to improve bio-nanocomposite mechanical properties and also demonstrated antimicrobial activity. Rhim et al. studied antimicrobial activity of chitosan/clay films prepared with two different types of nanoclays (i.e. a natural montmorillonite - MMT and an organically modified montmorillonite Cloisite 30B). It was shown that the materials prepared with the Cloisite 30B exhibited antibacterial activity against Gram-positive bacteria, but the natural MMT did not show any antibacterial activity (Rhim, Hong, Park, \& Ng, 2006).

Nanostructured starch materials have been mainly prepared by solution casting (Majdzadeh-Ardakani, Navarchian, \& Sadeghi, 2010), coprecipitation (Chung et al., 2010) and melt intercalation (Lee, Chen, \& Hanna, 2008). Starch films with Ag-NPs (7.8 mM) prepared by solution casting, where Ag-NPs were reduced using sodium borohydride proved to prevent the viability and growth of pathogens such as: Staphylococcus aureus, Escherichia coli and Candida albicans (Božanić et al., 2011).

According to literature, the incorporation of both organoclay and silver nanoparticles into polymer matrices, to achieve improved mechanical and barrier properties and antimicrobial activity was not yet studied. Therefore, the present work aims to develop a nanostructured starch based film containing C30B clay (3wt.\%) and silver nanoparticles with enhanced mechanical, barrier and antimicrobial properties. Nanocomposite films of clay/starch, silver/starch and silver/clay/starch (C30B/ST-NC, Ag-NPs/ST-NC and Ag-NPs/C30B/ST-NC) were prepared by solution casting method. The silver nanoparticles (Ag-NPs) were incorporated and synthesized in-situ by chemical reduction method. Clay dispersion in starch films was characterized by X-ray diffraction (XRD), scanning electron microscopy (SEM) and influence on mechanical properties assessed by dynamical mechanical analysis (Lan, Kaviratna \& Pinnavaia). As critical parameters for some applications, like food packaging, contact angle, color and opacity, permeability to water vapor $\left(\mathrm{PW}_{\text {vapor }}\right)$ and oxygen $\left(\mathrm{PO}_{2}\right)$ and contact tests were performed. Antimicrobial activity of the prepared nanostructured films was determined in order to evaluate the effect of different Ag-NPs concentrations.

\section{Experimental}

\subsection{Materials}

Native corn starch (ST) was kindly supplied by PIEP-Innovation in Polymer Engineering (Portugal). Silver nitrate $\left(\mathrm{AgNO}_{3}\right)$ and sodium borohydrate $\left(\mathrm{NaBH}_{4}\right)$ in powder state were used as received and supplied by Sigma Aldrich (St. Louis, MO, USA) and Acros Organics (Geel, Belgium), respectively. Cloisite ${ }^{\circledR}$ 30B (C30B) a montmorillonite modified with a quaternary ammonium salt (MT2EtOH = methyl tallowyl bis-2-hydroxyethyl ammonium chloride), was used as received and supplied by Southern Clay Products, Inc. (Texas, USA).

\subsection{Film preparation}

\subsubsection{C30B dispersion in ST solution (C30B/ST)}

An aqueous starch solution $(10 \mathrm{~g} / \mathrm{L})$ was heated at $70-80^{\circ} \mathrm{C}$ until the complete dissolution of starch. Then, $3 \mathrm{wt} . \%$ of C30B was added and the mixture was sonicated using an ultrasonic probe, at room temperature, for $1 \mathrm{~h}$. Percentage amplitude of $100 \%$ as power delivery was used. An ultrasonic processor UP100H with a MS7D flow tip 7 (Teltow, Germany) was used with a $30 \mathrm{kHz}$ frequency.

\subsection{2. $\mathrm{Ag}-\mathrm{NPS} / \mathrm{C} 30 \mathrm{~B} / \mathrm{ST}-\mathrm{NC}$ films preparation}

Ag-NPs/C30B/ST-NC films were prepared as follows: $25 \mathrm{~mL}$ of the C30B/ST dispersed solution (please see Section 2.2.1) and different concentration of silver nitrate $(0.3,0.5,0.8$ and $1.0 \mathrm{mM})$ were mixed and left stirring during $5 \mathrm{~min}$. Then, the reducing agent, sodium borohydride, was slowly added at the same concentrations as silver nitrate. The color of the prepared solutions with different concentration of $\mathrm{AgNO}_{3}$ changed from colorless to light brown then to brown and finally to dark brown, indicating the formation of Ag-NPs in C30B/ST solution. All the mixtures were boiled during 5 min, including ST and C30B/ST solution as controls. Ag-NPs/STNC nanostructured films were prepared using the same procedure without the addition of C30B to ST solution.

Different concentrations of silver/starch (Ag-NPs/ST-NC), silver/clay/starch (Ag-NPs/C30B/ST-NC) solutions ( $25 \mathrm{~mL}$ each) were spilled in glass plates $(7.0 \times 1.5 \mathrm{~cm})$. All solutions were dried at room temperature for $48 \mathrm{~h}$ and then placed in an oven at $25^{\circ} \mathrm{C}$ in vacuum for one additional day (Fig. 1). The mean diameter of the prepared films was adjusted to the same size. All films were conditioned at $50 \%$ relative humidity and room temperature before analysis. The same procedure was applied to starch and to clay/starch (C30B/ST-NC) solutions as blanks (Fig. 1).

\subsection{Characterization}

\subsection{1. $X R D$}

X-ray diffraction measurements (XRD) were performed to evaluate the dispersion of $\mathrm{C} 30 \mathrm{~B}$ in the starch films. XRD spectra of the samples were obtained at room temperature using a diffractometer (AXS Nanostar- D8 Discover, Bruker) equipped with a $\mathrm{CuK \alpha}$ generator $(\lambda=1.5406 \AA)$ at $40 \mathrm{~mA}$ and $40 \mathrm{kV}$. Data were collected in a range of 0.08 to $10^{\circ}$ with a step size of $0.01^{\circ}$ and a counting time of $2 \mathrm{~s}$ per step. The clay powder or starch nanocomposite films were analyzed directly. The Bragg's law $\left(n \lambda=2 d_{001} \sin \theta\right)$ was used to determine the clay interlayer distance $d_{001}$, where $d$ is the spacing between silica layers of the clay (also called interlayer spacing), $\lambda$ the wavelength of X-ray on the silica layer, and $n$ is a whole number which represents the order of diffraction, taken 1 in our calculations.

\subsubsection{SEM}

Scanning electron microscopy (SEM) was carried out to examine the surface morphology of starch nanocomposites. The SEM analysis was performed in a Leica Cambridge S360 microscope in back-scatter mode. The samples were previously fractured in liquid nitrogen and coated with a gold thin film.

\subsubsection{DMA}

Dynamic mechanical analyses (DMA) (Lan, Kaviratna \& Pinnavaia) experiments were performed in a TRITON apparatus in tension mode with the following parameters: frequency $=1 \mathrm{~Hz}$; scan rate $=2^{\circ} \mathrm{C} / \mathrm{min}$; temperature range $=-70$ to $100^{\circ} \mathrm{C}$; free length $=15 \mathrm{~mm}$ and value tension $=15 \mu \mathrm{m}$. The equipment was calibrated according to the standard procedure. The tests were performed on $3 \times 30 \mathrm{~mm}$ rectangular samples in a longitudinal direction. At least two specimens of each sample were tested.

\subsubsection{Color and opacity}

Color and opacity of the films were evaluated using a Konica Minolta, Chroma Meter (CR 410; Konica Minolta, Japan). The CIELab scale was used to determined $L^{*}, a^{*}$ and $b^{*}$ color parameters. $L^{*}$ is the vertical coordinate of a three-dimensional system of colors, which has values from 0 (black) to 100 (for white), $a^{*}$ is the horizontal coordinate the values of which range from -80 (green) to +80 (red) and $b^{*}$ is the horizontal coordinate the values of which range from -80 (blue) to +80 (yellow). The opacity $(Y)$ was determined according to the Hunterlab method (Hunterlab, 2008), as the ratio 


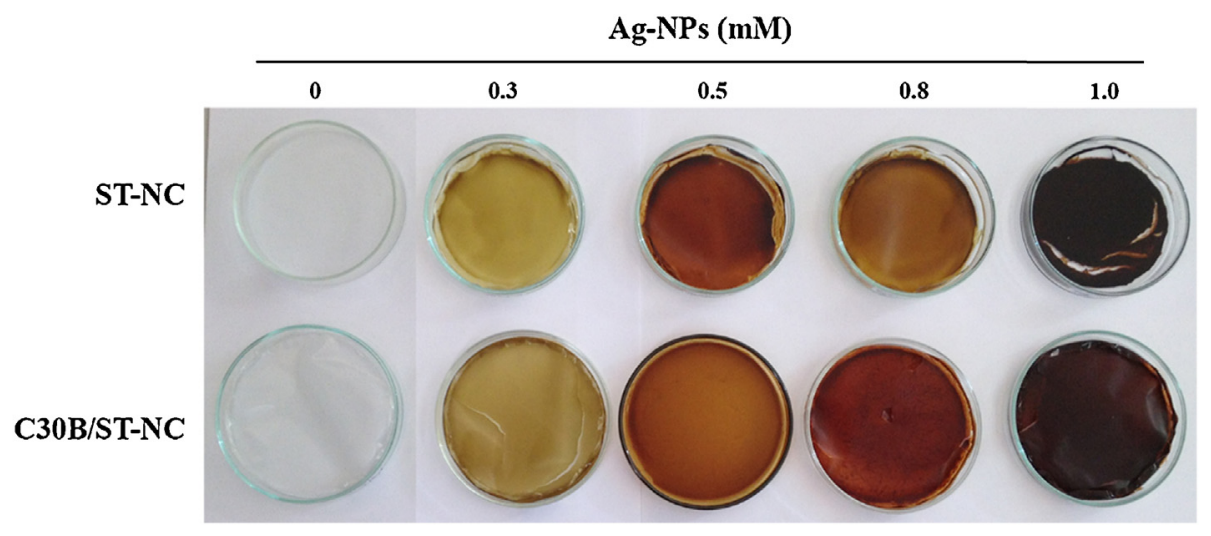

Fig. 1. Nanostructured starch films.

between the opacity of each sample on the black standard $\left(Y_{b}\right)$ and the opacity of each sample on the white standard $\left(Y_{w}\right)$. The results were expressed as a percentage: $Y(\%)=100\left(Y_{b} / Y_{w}\right)$. From three replicates of each film sample were determined at random three measurements, $L^{*}, a^{*}, b^{*}, Y_{b}$ and $Y_{W}$ and an average of each one was used for calculation.

\subsubsection{Contact angle}

The influence of chemical modification on the surface polarity of starch films was studied by means of contact angle measurements. The Young-Laplace method for the water drop was used to determine the contact angle (Krishnan et al., 2005). One drop of $3 \mu \mathrm{L}$ was placed on the surface of the films and a Contact Angle System OCA 15 Plus with CCD video camera (resolution of $752 \times 582$ pixel) and C20 software was used. The contact angle was calculated from the shape of the drop according to the following equation: $\theta=2 \tan ^{-1}(2$ $h / d$ ), where $h$ and $d$ are the height and diameter of the water drop, respectively. Four measurements were performed for each material.

\subsubsection{Permeability to gases}

Water vapor permeability ( $\left.\mathrm{PW}_{\text {vapor }}\right)$ was determined by gravimetric method based on Casariego et al. (2009) procedure. Film samples were placed on top of cups containing $50 \mathrm{~mL}$ of distilled water and properly sealed (films were sealed by the edges using a sealant ring), being the initial weight determined. Afterwards samples were placed inside a desiccator containing silica gel $(0 \% \mathrm{RH}$; $20^{\circ} \mathrm{C}$ ), using a fan to guarantee the homogenization of the gases inside the desiccator (Duncan, 2011). To monitor weight loss over time, periodical cup weightings ( $2 \mathrm{~h}$ ) were performed until steady state was reached. Water vapor transmission rate (WVTR) was calculated by dividing the slope of the linear regression of weight loss by film area, and $\mathrm{PW}_{\text {vapor }}(\mathrm{g} / \mathrm{m} \mathrm{s} \mathrm{Pa})$ was calculated as follows:

$\mathrm{PW}_{\text {vapor }}=\frac{\mathrm{WVTR} \times L}{\Delta p}$

where $L$ is film thickness ( $\mathrm{m}$ ) and $\Delta p$ is water vapor partial pressure difference $(\mathrm{Pa})$ across the two sides of the film.

Oxygen permeability $\left(\mathrm{PO}_{2}\right)$ measurements were conducted based on Cerqueira, Souza, Teixeira, and Vicente (2012) method. The tests were performed at $20^{\circ} \mathrm{C}$ in a gas permeation cell composed by two chambers with test film placed between them. The permeation gas, oxygen, flowed continuously through the lower chamber, and nitrogen (as a sweep gas) was passed through the upper chamber. When the steady state was reached, the penetrated $\mathrm{O}_{2}$ in the sweep gas stream was analyzed by gas chromatography (Chrompack 9001, Middelburg, Netherlands) at $110^{\circ} \mathrm{C}$ with a column Porapak Q 80/100 mesh $2 \mathrm{~m} \times 1 / 8$ in. $\times 2 \mathrm{~mm}$ SS equipped with a hydrogen flame ion detector. Helium was used as carrier gas at $23 \mathrm{~mL} / \mathrm{min}$. A standard mixture containing $10 \%$ of $\mathrm{CO}_{2}, 20 \%$ of $\mathrm{O}_{2}$ and $70 \%$ of $\mathrm{N}_{2}$ was used for calibration.

For all determinations, at least three repetitions were made for each type of film.

\subsection{Statistical analysis}

Statistical analysis was performed using the analysis of variance (Mulinacci et al., 2008) procedure with SigmaPlot 11.0 software for Windows. Tukey's test was applied to detect differences of means, and $p<0.05$ was considered to be statistically significant.

\subsection{Antimicrobial evaluation}

Antimicrobial properties were evaluated based on disc diffusion assay widely used to evaluate antimicrobial properties of films (Hema, Ng, \& Amirul, 2012; Heydari, Alemzadeh, \& Vossoughi, 2013; Maizura, Fazilah, Norziah, \& Karim, 2007). Film samples and blank sample of filter paper were prepared in discs of $8 \mathrm{~mm}$ in diameter and sterilized under ultraviolet light. Gram-positive bacteria (S. aureus CECT 976), Gram-negative bacteria (E. coli CECT 4210) and Yeast (C. albicans ATCC 90028) were used in the antimicrobial activity tests. Inoculums were prepared by suspending overnight cultures into the phosphate buffered saline (PBS) solution with approximately $10^{5} \mathrm{CFU} / \mathrm{mL}$. The resulting suspensions were swapped using sterile cotton bud over the entire surface of culture plates containing Mueller Hinton Agar (Merck, Darmstadt, Germany) for bacteria and YPD agar (Sigma, St. Louis, MO, USA) for yeast. This procedure was repeated four times by rotating the plate at $45^{\circ}$ after each application ensuring an even distribution of the inoculums on the agar surface. The film samples were placed on the surface of inoculated agar plate by using a sterile tweezers and gently pressed to ensure full contact to agar surface. The plates were then incubated at $37^{\circ} \mathrm{C}$ for $24 \mathrm{~h}$, then the zone where the film was placed and its surroundings were carefully observed. All the assays were taken in triplicate.

\subsection{Contact test}

Nanostructured starch films were exposed to a $3 \%(\mathrm{w} / \mathrm{v})$ acetic acid solution (food simulant) at $\mathrm{pH} 2.5$ heated at $40^{\circ} \mathrm{C}$ during 10 days in an electrical furnace, according to EN 1186-1 (EN1186-1, 2002). The acid solution was recovery and aluminium, iron, silver and calcium were quantified by Inductively Coupled Plasma Optical Emission Spectrometry technique (ICP-OES, iCAP ${ }^{\mathrm{TM}} 7600$, Thermo scientific). 


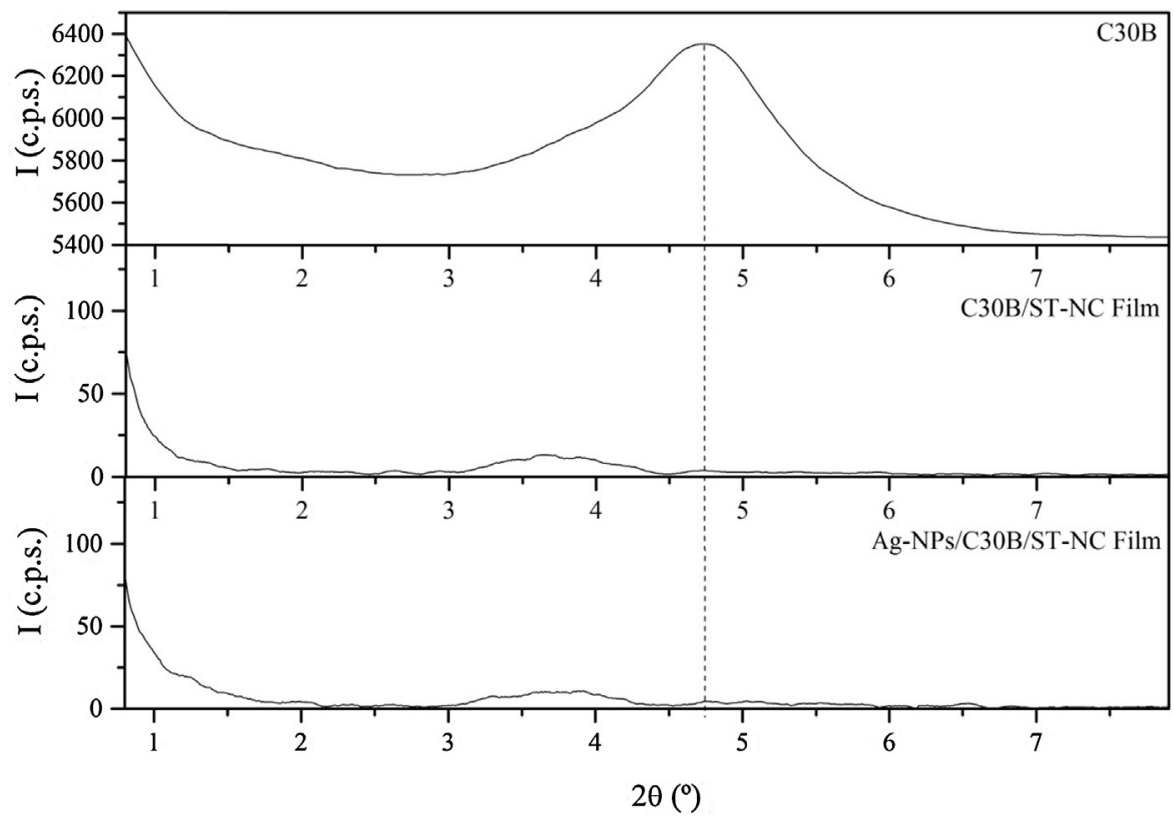

Fig. 2. X-ray diffraction patterns of organo-modified clay C30B, C30B/ST-NC and Ag-NPs/C30B/ST-NC films.

A
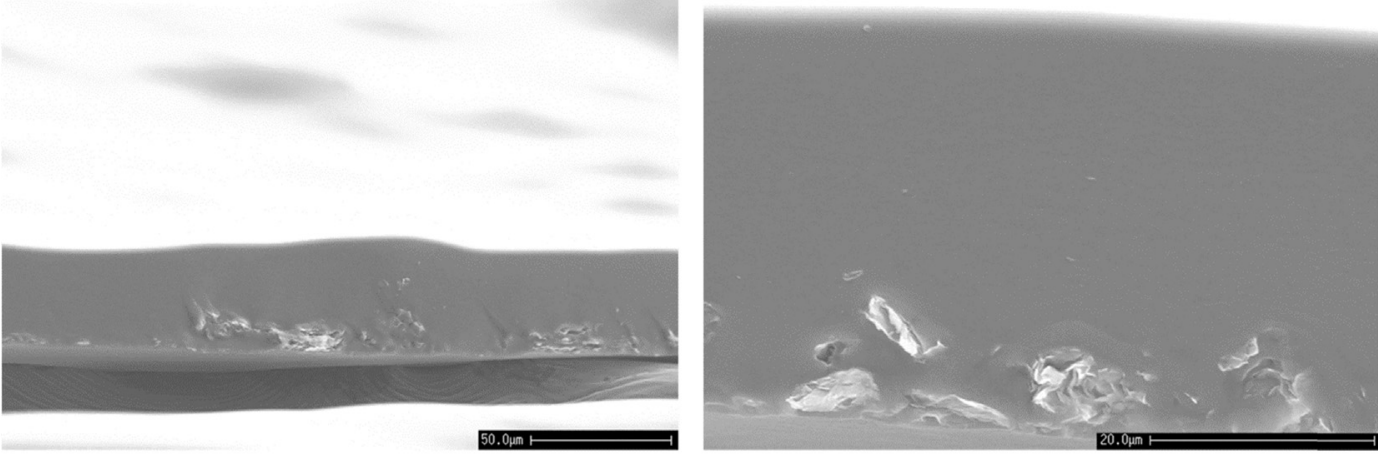

B
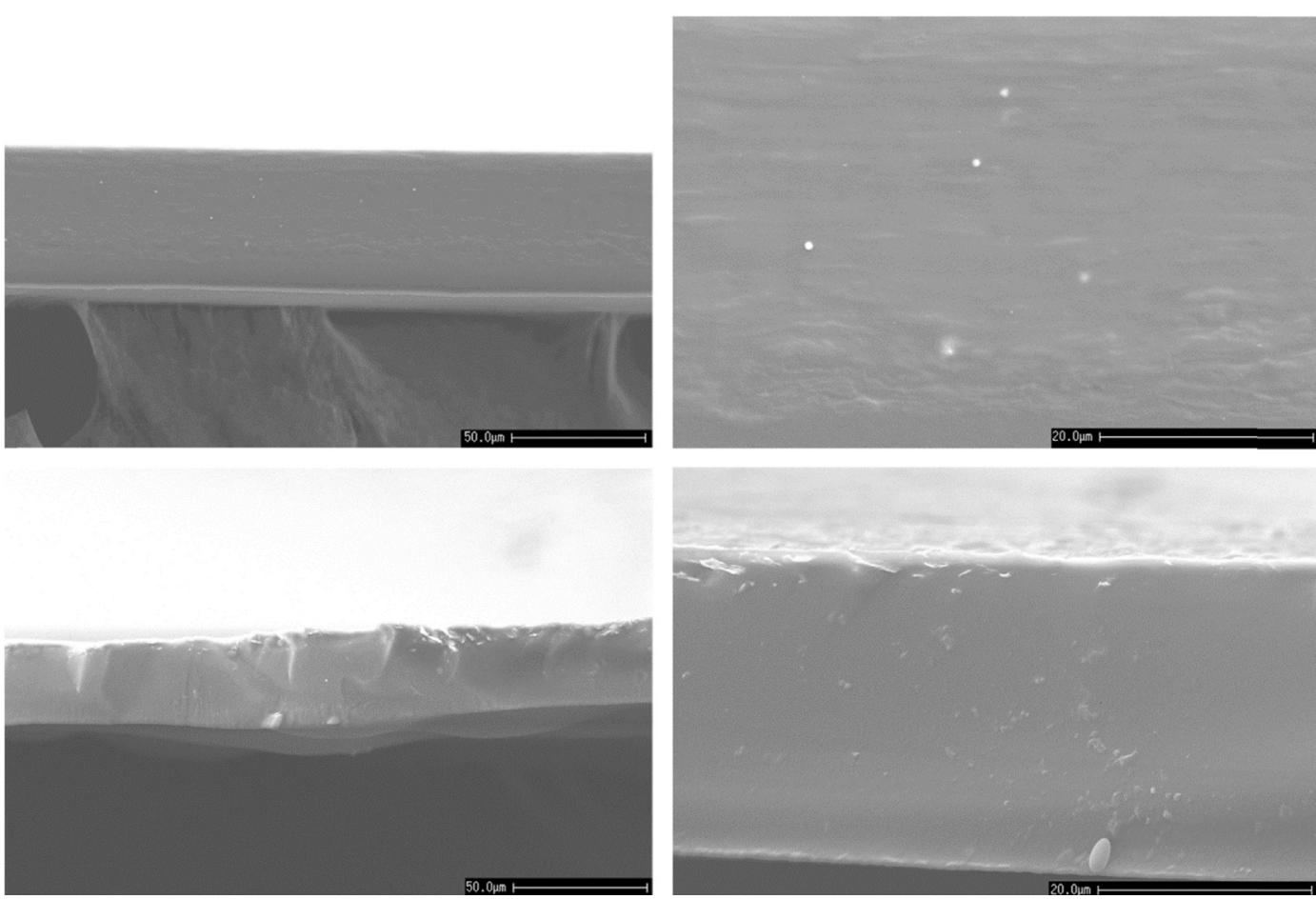

Fig. 3. Morphology of C30B/ST-NC (A), Ag-NPs/ST-NC (B) and Ag-NPs/C30B/ST-NC (C) films. 
Table 1

Color parameters and opacity values of the films with C30B and Ag-NPs.

\begin{tabular}{|c|c|c|c|c|}
\hline Sample & $L^{*}$ & $a^{*}$ & $b^{*}$ & $Y(\%)$ \\
\hline ST & $98.18 \pm 0.26^{\mathrm{a}}$ & $0.10 \pm 0.02^{\mathrm{a}}$ & $2.10 \pm 0.03^{a}$ & $11.55 \pm 0.59^{\mathrm{a}}$ \\
\hline C30B/ST-NC & $96.40 \pm 0.65^{\mathrm{a}}$ & $0.07 \pm 0.02^{\mathrm{a}}$ & $2.26 \pm 0.06^{\mathrm{a}}$ & $11.51 \pm 0.62^{\mathrm{a}}$ \\
\hline Ag-NPs/ST-NC (0.3 mM Ag) & $70.79 \pm 1.94^{b}$ & $8.96 \pm 4.86^{\mathrm{b}}$ & $61.21 \pm 3.09^{b}$ & $16.37 \pm 2.32^{\mathrm{a}}$ \\
\hline Ag-NPs/ST-NC (1.0 mM Ag) & $31.82 \pm 3.86^{c}$ & $9.55 \pm 2.83^{b}$ & $7.68 \pm 3.58^{\mathrm{a}}$ & $82.85 \pm 5.99^{b}$ \\
\hline Ag-NPs/C30B/ST-NC (0.3 mM Ag) & $70.16 \pm 3.06^{\mathrm{b}}$ & $5.54 \pm 5.04^{\mathrm{ab}}$ & $53.45 \pm 21.26^{b}$ & $19.87 \pm 2.44^{\mathrm{a}}$ \\
\hline Ag-NPs/C30B/ST-NC (1.0 mM Ag) & $32.36 \pm 1.21^{\mathrm{c}}$ & $12.19 \pm 3.62^{\mathrm{b}}$ & $8.63 \pm 1.63^{\mathrm{a}}$ & $73.12 \pm 11.83^{b}$ \\
\hline
\end{tabular}

a-c Mean \pm SD followed by the same letter in the same column are not statistically different according to Tukey's test ( $\alpha=0.05)$.

\section{Results and discussion}

\subsection{Dispersion assessment}

The clay dispersion in the nanostructured films was investigated using X-ray diffractometer (XRD) and scanning electron microscopy (SEM). XRD analysis of neat C30B, C30B/ST-NC film and Ag-NPs/C30B/ST-NC film are presented in Fig. 2. The mean interlayer spacing of the $(001)$ plane $\left(d_{001}\right)$, using Bragg law, for the neat $\mathrm{C} 30 \mathrm{~B}$ clay solid obtained was $1.86 \mathrm{~nm}\left(2 \theta=4.75^{\circ}\right)$. X-ray results demonstrate a significant shift of the diffraction peak to lower angles, $3.63^{\circ}$ for $\mathrm{C} 30 \mathrm{~B} / \mathrm{ST}-\mathrm{NC}$ and $3.67^{\circ}$ for $\mathrm{Ag}-\mathrm{NPs} / \mathrm{C} 30 \mathrm{~B} / \mathrm{ST}-$ NC, suggesting that an ordered intercalated and/or exfoliated (at least partially) was achieved (Fig. 2). Applying the Bragg's law, a clay interlayer distance of $d_{001}=2.43 \mathrm{~nm}$ for C30B/ST-NC and $d_{001}=2.41 \mathrm{~nm}$ for Ag-NPs/C30B/ST-NC were obtained, in contrast of 1.86 to neat $\mathrm{C30B}$. These values suggest that the starch chains penetrate into the silicate layers increasing the distance between clay stacks ( $d$-spacing). This can be associated to the hydroxyl groups present in the starch, which improved the interaction with the clay. Moreover, the sonication method applied to C30B/ST before solution casting, was critical to improve intercalated structures. The addition of Ag-NPs to nanostructure C30B/ST films, induce a small variation of the peak intensity, which can be associated with a more exfoliated structure. A possible explanation is that the Ag-NPs are dispersed among the clay interlamellar structure, contributing to clay dispersion.

SEM micrographs of C30B/ST-NC, Ag-NPs/ST-NC and AgNPs/C30B/ST-NC films are depicted in Fig. 3. Exfoliated clay layers coexisting with some organoclay agglomerates located at the bottom of the starch film (C30B/ST-NC) can be detected (Fig. 3A). The presence of some clay agglomerates can be related with the film preparation method, solution casting, and to the slow solvent evaporation, which led to some clay deposition. This is not in agreement with XRD results discussed above, which suggest that the film has a high homogeneity. The difference in the results obtained by both techniques can be due to the area analyzed by each one. XRD was performed only on the film surface, while SEM was executed in the transversal cut film surface.

SEM micrographs of Ag-NPs/ST-NC film (Fig. 3B), in different magnification, show that Ag-NPs, as white dots, were successfully formed and are uniformly dispersed in the films. SEM images demonstrate that the incorporation of Ag-NPs into C30B/ST-NC (AgNPs/C30B/ST-NC film, Fig. 3C) improved the clay dispersion in the polymer matrix. No clay aggregation can be seen even at higher magnifications (Fig. 3C). SEM results are in agreement with X-ray data obtained for Ag-NPs/C30B/ST-NC film. Therefore, the incorporation of both nanoparticles, Ag-NPs and C30B, had a synergetic effect, resulting in a material with higher homogeneity and better clay dispersion.

\subsection{Dynamic mechanical analysis}

Mechanical properties of starch and of the most promisor Ag-NPs/C30B/ST-NC film were assessed by dynamic mechanical

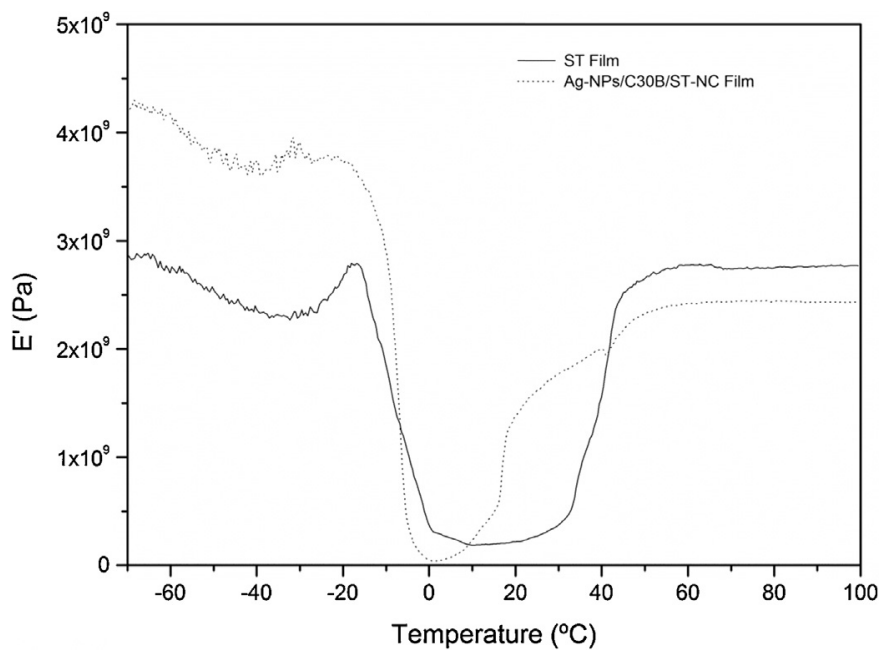

Fig. 4. Storage modulus of ST and Ag-NPs/C30B/ST-NC films as a function of temperature.

analysis (Lan, Kaviratna \& Pinnavaia). Since C30B/ST-NC film revealed different clay dispersion in XRD and SEM analysis, mechanical test for this film was not performed. Fig. 4 depicts the plot of the temperature dependence of storage modulus $\left(E^{\prime}\right)$ for neat ST and Ag-NPs/C30B/ST-NC films. Ag-NPs/C30B/ST-NC film exhibits an increase of $E^{\prime}$ values ( $33 \%$ ) when compared to the starch film. It is known that the effect of the clay in polymer matrices results in the increase of the modulus or stiffness via reinforcement mechanisms described by composites theories (Fornes \& Paul, 2003; Lee \& Paul, 2005). A possible explanation for the improvement of the $E^{\prime}$ even at temperatures above the room temperature could be the formation of a three-dimensional network of interconnected long silicate layers, strengthening the material through mechanical percolation (Lan, Kaviratna, \& Pinnavaia, 1994). The presence of clay nanoparticles improved the mechanical properties of the starch, as discussed by other authors (Avella et al., 2005). The good clay dispersion in the presence of Ag-NPs, confirmed by XRD and SEM in Ag-NPs/C30B/ST-NC film, lead to enhanced mechanical properties of the developed nanostructured ST film.

\subsection{Color and opacity}

Table 1 presents the color and opacity values of the films containing C30B and Ag-NPs at different concentrations (Fig. 1). The results indicated that the addition of clay does not lead to statistically significant changes $(p>0.05)$ in color and opacity values. Still, the incorporation of Ag-NPs changes $(p<0.05)$ color and opacity values of the films. Lightness $\left(L^{*}\right)$ decreases with the increase of Ag-NPs concentration being statistically different $(p<0.05)$ for all tested concentrations. Ag-NPs $(0.3 \mathrm{mM})$ lead to an increase of $b^{*}$ and a moderate increase of $a^{*}$ when compared to ST films, due to a shift from milt transparent to a yellow/orange color. For Ag-NPs $(1.0 \mathrm{mM})$ the opacity values $(\mathrm{Y})$ increased $(p<0.05)$, 
Table 2

Values of oxygen $\left(\mathrm{PO}_{2}\right)$ and water vapor ( $\left.\mathrm{PW}_{\text {vapor }}\right)$ permeability and water contact angle for ST and ST-NC films.

\begin{tabular}{|c|c|c|c|}
\hline \multirow[t]{2}{*}{ Sample } & \multicolumn{2}{|c|}{ Permeability ( $\mathrm{g} / \mathrm{m} \mathrm{s} \mathrm{Pa} \times 10^{10}$ ) } & \multirow[t]{2}{*}{ Water contact angle $\left({ }^{\circ}\right)$} \\
\hline & $\mathrm{PO}_{2}$ & $\mathrm{PW}_{\text {vapor }}$ & \\
\hline ST & $1.53 \pm 0.20^{\mathrm{a}}$ & $1.34 \pm 0.20^{\mathrm{a}}$ & \\
\hline C30B/ST-NC & $1.30 \pm 0.25^{\mathrm{a}}$ & $1.15 \pm 0.19^{\mathrm{a}}$ & $57.6 \pm 2.0$ \\
\hline Ag-NPs/ST-NC (0.3 mM Ag) & $1.50 \pm 0.24^{\mathrm{a}}$ & $1.30 \pm 0.16^{\mathrm{a}}$ & $82.8 \pm 0.7$ \\
\hline Ag-NPs/ST-NC (1.0 mM Ag) & $1.36 \pm 0.17^{\mathrm{a}}$ & $1.12 \pm 0.20^{\mathrm{a}}$ & $57.6 \pm 1.1$ \\
\hline Ag-NPs/C30B/ST-NC (0.3 mM Ag) & $1.10 \pm 0.22^{\mathrm{a}}$ & $1.01 \pm 0.21^{\mathrm{a}}$ & $54.4 \pm 1.8$ \\
\hline Ag-NPs/C30B/ST-NC (1.0 mM Ag) & $1.00 \pm 0.21^{\mathrm{a}}$ & $0.90 \pm 0.33^{\mathrm{a}}$ & $45.3 \pm 2.2$ \\
\hline
\end{tabular}

${ }^{\text {a }}$ Mean \pm SD followed by the same letter in the same column are not statistically different according to Tukey's test $(\alpha=0.05)$.

presenting statistical differences $(p<0.05)$ regarding the results obtained with other films. Moreover, $b^{*}$ values decreased and $a^{*}$ values kept the same magnitude, being the films predominantly orange. As Ag-NPs concentration increases, the low lightness and opacity of dark and matte films increases resulting in higher values variance, as it is evident by the high standard deviation obtained for color parameters (Table 1 ).

\subsection{Water contact angle and permeability}

The water contact angle measurements allow to evaluate the incorporation effect of Ag-NPs and C30B on films surface polarity. Usually, water contact angle is used as an indicator of the degree of surface hydrophobicity or hydrophilicity (Su, Huang, Yuan, Wang, \& Li, 2010). Films with water contact angle higher than $65^{\circ}$ are identified as hydrophobic surfaces (Vogler, 1998). Contact angle data are presented in Table 2. The incorporation of C30B leads to a significant $(p<0.05)$ decrease of contact angle value, suggesting an increase of polarity, due to the incorporation of more hydrophilic groups of the clay. While the incorporation of $0.3 \mathrm{mM}$ of Ag-NPs did not increased $(p>0.05)$ the film hydrophilicity, the addition of $1.0 \mathrm{mM}$ of Ag-NPs increased significantly $(p>0.05)$ the contact angle. Better results were obtained, i.e., lower values of contact angles, when both nanoparticles were added. Actually the more hydrophilic surface was achieved for the Ag-NPs/C30B/ST-NC film.

It has been reported that the addition of clay or metal nanoparticles to polymeric matrices affects its gas permeability (Casariego et al., 2009; Rhim et al., 2006). These particles have the ability to act as oxygen barrier, controlling oxygen transport to extend the food shelf-life. Moreover, in most the cases of food packaging, it is desired to avoid or at least to decrease moisture transfer between the food and the surrounding atmosphere, $\mathrm{PW}_{\text {vapor }}$ should be as low as possible (Shen, $\mathrm{Wu}$, Chen, \& Zhao, 2010). Table 2 summarizes the values obtained for $\mathrm{PW}_{\text {vapor }}$ and $\mathrm{PO}_{2}$ for ST and ST nanostructured films. The incorporation of $\mathrm{C} 30 \mathrm{~B}$ or Ag-NPs $(1.0 \mathrm{mM})$ decreases around $15 \%$ the ST $\mathrm{PW}_{\text {vapor }}$ and $\mathrm{PO}_{2}$ permeability. However, better barrier properties were achieved for the nanostructure starch films containing both nanoparticles (Ag-NPs and C30B). While the presence of $0.3 \mathrm{mM} \mathrm{Ag}$ (Ag-NPs/C30B/ST-NC) induces about $27 \%$ permeability reduction, with $1 \mathrm{mM} \mathrm{Ag}$ (Ag-NPs/C30B/ST-NC) the reduction is $34 \%$. The barrier properties improvement, when both nanoparticles were presented can be associated to the morphology accomplished, as observed by XRD and SEM.

\subsection{Antimicrobial activity}

Antimicrobial properties of ST, C30B/ST-NC, Ag-NPs/ST-NC and Ag-NPs/C30B/ST-NC at 0.3, 0.5, 0.8 and $1.0 \mathrm{mM}$ of Ag-NPs were evaluated against $S$. aureus, E. coli and C. albicans. As expected, the results revealed no inhibition halo when starch films are used, confirming that starch have no antimicrobial effect. For the film containing C30B (C30B/ST-NC) a decrease of microbial growth was observed (Table 3). Although, antimicrobial effect was not detected in the case of $C$. albicans, where it was observed a microbiological

Table 3

Antimicrobial activity of the tested films against C. albicans, S. aureus and E. coli.

\begin{tabular}{|c|c|c|c|c|c|c|}
\hline & ST & C30B/ST-NC & Ag-NPs/ST-NC $0.3 \mathrm{mM}$ & Ag-NPs/ST-NC $1 \mathrm{mM}$ & Ag-NPs/C30B/ST-NC $0.3 \mathrm{mM}$ & Ag-NPs/C30B/ST-NC $1 \mathrm{mM}$ \\
\hline \multicolumn{7}{|c|}{ C. albicans } \\
\hline & Growth & Growth & Inhibition & Inhibition & Inhibition & Inhibition \\
\hline \multicolumn{7}{|c|}{ S. aureus } \\
\hline & Growth & Inhibition & Inhibition & Inhibition & Inhibition & Inhibition \\
\hline \multicolumn{7}{|l|}{ E. coli } \\
\hline & Growth & Inhibition & Inhibition & Inhibition & Inhibition & Inhibition \\
\hline
\end{tabular}


Table 4

Elements content in the liquid food simulant after contact with nanostructured starch films.

\begin{tabular}{llll}
\hline \multirow{2}{*}{ Element } & \multicolumn{2}{l}{ Weight $(\mathrm{mg} / \mathrm{g})$} & \\
\cline { 2 - 4 } & $\mathrm{C} 30 \mathrm{~B} / \mathrm{ST}-\mathrm{NC}$ & $\mathrm{Ag}-\mathrm{NPs} / \mathrm{ST}-\mathrm{NC}$ & $\mathrm{Ag}-\mathrm{NPs} / \mathrm{C} 30 \mathrm{~B} / \mathrm{ST}-\mathrm{NC}$ \\
\hline $\mathrm{Al}$ & 0.28 & 0.03 & 0.10 \\
$\mathrm{Ca}$ & $<\mathrm{QL}$ & $<\mathrm{QL}$ & $<\mathrm{QL}$ \\
$\mathrm{Fe}$ & 0.08 & 0.04 & 0.09 \\
$\mathrm{Ag}$ & 0.03 & 0.70 & 0.40 \\
\hline
\end{tabular}

QL-quantification limit.

growth. C30B antimicrobial effect against bacteria can be explained by the release of ammonium salts from the nanoclay which affects the bacteria sensitive targets (Martins et al., 2013). For the samples containing Ag-NPs (Ag-NPs/ST-NC and Ag-NPs/C30B/ST-NC) no microorganism growth was observed in the film contact area for all tested concentrations, resulting from the interaction between $\mathrm{Ag}^{+}$and the mercapto groups of the bacterial protein (Sun et al., 2011). However, no inhibition halo was detected, suggesting that no diffusion of the active compounds occurred to agar.

Thus, the presence of $\mathrm{C} 30 \mathrm{~B}$ leads to a bacteriostatic effect (against $S$. aureus and E. coli), while for nanocomposite films with C30B and Ag-NPs a microbiostatic effect (against S. aureus, E. coli and $C$. albicans) was observed. Moreover, the absence of an inhibition halo, even at higher concentration of Ag-NPs, suggests a good entrapment of the active compounds in the nanocomposite film matrix (i.e. the release of the compounds from the matrix would lead to the presence of an inhibition halo).

\subsection{Contact test}

Contact tests using food simulants were performed to determine if the nanostructured starch films fulfil the recent regulations and European directives on food packaging (EN1186-1, 2002), according to the Commission Regulation No. 10/2011, which establishes the overall migration limits (OML). For plastic materials, the OML is $60 \mathrm{mg}$ (of substances) $/ \mathrm{kg}$ (of foodstuff or food simulant) for all substances as maximum migration. The migration of $\mathrm{Al}, \mathrm{Ca}, \mathrm{Fe}$ or $\mathrm{Ag}$ to the food simulant (Table 4) was not significant. The OML result $(42.9 \mathrm{mg} / \mathrm{kg}$ ) obtained also confirmed that the films accomplish the requirements for food packaging. These results are in agreement with the antimicrobial test, were the absence of an inhibition hallo demonstrates the entrapment of active compounds. The above data indicate that the produced films are safe and can be used in food contact.

\section{Conclusion}

Starch based nanostructured films with antimicrobial properties and improved mechanical and barrier properties were successfully achieved. Among all the compositions studied, the AgNPs/C30B/ST-NC film with $0.3 \mathrm{mM}$ Ag-NPs revealed to be the most appropriated.

The presence of Ag-NPs not only gave bacteriostatic effect but also enhanced $\mathrm{C} 30 \mathrm{~B}$ dispersion and changed the surface polarity. Incorporation of $\mathrm{C} 30 \mathrm{~B}$ and $\mathrm{Ag}-\mathrm{NPs}$ (at lower concentration, $0.3 \mathrm{mM}$ ) in ST film showed to be enough to improved mechanical and gas barrier properties with antimicrobial results similar to higher Ag-NPs concentrations. Moreover, the Ag-NPs/C30B/STNC film incorporating $0.3 \mathrm{mM} \mathrm{Ag-NPs} \mathrm{did} \mathrm{not} \mathrm{affected} \mathrm{significantly}$ color and opacity of the ST films. Therefore, the Ag-NPs/C30B/ST-NC film has high potential applicability as safety food package, since migration limits were fulfilled.

\section{Acknowledgments}

The authors acknowledge the n-STeP Project, NORTE-070124-FEDER-000039, supported by the Programa Operacional Regional do Norte (ON.2), PEst-C/CTM/LA0025/2013 (Strategic Project-LA 25-2013-2014), PEst-OE/EQB/LA0023/2013 and the Project "BioInd - Biotechnology and Bioengineering for improved Industrial and Agro-Food processes", REF. NORTE-07-0124-FEDER000028 Co-funded by the Programa Operacional Regional do Norte (ON.2 - O Novo Norte), QREN, FEDER. The author Miguel A. Cerqueira is recipient of a fellowship (SFRH/BPD/72753/2010, respectively), supported by Fundação para a Ciência e Tecnologia, POPH-QREN and FSE (FCT, Portugal).

\section{References}

Avella, M., De Vlieger, J. J., Errico, M. E., Fischer, S., Vacca, P., \& Volpe, M. G. (2005). Biodegradable starch/clay nanocomposite films for food packaging applications. Food Chemistry, 93(3), 467-474.

Božanić, D. K., Djoković, V., Dimitrijević-Branković, S., Krsmanović, R., McPherson, M., Nair, P. S., et al. (2011). Inhibition of microbial growth by silver-starch nanocomposite thin films. Journal of Biomaterials Science, Polymer Edition, 22(17), 2343-2355

Casariego, A., Souza, B. W. S., Cerqueira, M. A., Teixeira, J. A., Cruz, L., Díaz, R., et al. (2009). Chitosan/clay films' properties as affected by biopolymer and clay micro/nanoparticles' concentrations. Food Hydrocolloids, 23(7), 1895-1902.

Cerqueira, M., Souza, B. S., Teixeira, J., \& Vicente, A. (2012). Effects of interactions between the constituents of chitosan-edible films on their physical properties. Food and Bioprocess Technology, 5(8), 3181-3192.

Cho, K.-H., Park, J.-E., Osaka, T., \& Park, S.-G. (2005). The study of antimicrobial activity and preservative effects of nanosilver ingredient. Electrochimica Acta, 51(5), 956-960.

Chung, Y.-L., Ansari, S., Estevez, L., Hayrapetyan, S., Giannelis, E. P., \& Lai, H.-M.(2010). Preparation and properties of biodegradable starch-clay nanocomposites. Carbohydrate Polymers, 79(2), 391-396.

Darder, M., Aranda, P., \& Ruiz-Hitzky, E. (2007). Bionanocomposites: A new concept of ecological, bioinspired, and functional hybrid materials. Advanced Materials, 19(10), 1309-1319.

Duncan, T. V. (2011). Applications of nanotechnology in food packaging and food safety: Barrier materials, antimicrobials and sensors. Journal of Colloid and Interface Science, 363(1), 1-24.

EN. (2002). Materials and articles in contact with food stuffs-Plastics. In EN1186-1. EN.

Fornes, T. D., \& Paul, D. R. (2003). Modeling properties of nylon 6/clay nanocomposites using composite theories. Polymer, 44(17), 4993-5013.

Hema, R., Ng, P. N., \& Amirul, A. A. (2012). Green nanobiocomposite: Reinforcement effect of montmorillonite clays on physical and biological advancement of various polyhydroxyalkanoates. Polymer Bulletin, 70(3), 755-771.

Heydari, A., Alemzadeh, I., \& Vossoughi, M. (2013). Functional properties of biodegradable corn starch nanocomposites for food packaging applications. Materials E' Design, 50, 954-961.

Hunterlab. (2008). Applications Note, 9(3), 2.

Krishnan, A., Liu, Y.-H., Cha, P., Woodward, R., Allara, D., \& Vogler, E. A. (2005). An evaluation of methods for contact angle measurement. Colloids and Surfaces B: Biointerfaces, 43(2), 95-98.

Lan, T., Kaviratna, P. D., \& Pinnavaia, T. J. (1994). On the nature of polyimide-clay hybrid composites. Chemistry of Materials, 6(5), 573-575

Lee, K. Y., \& Paul, D. R. (2005). A model for composites containing three-dimensional ellipsoidal inclusions. Polymer, 46(21), 9064-9080.

Lee, S. Y., Chen, H., \& Hanna, M. A. (2008). Preparation and characterization of tapioca starch-poly(lactic acid) nanocomposite foams by melt intercalation based on clay type. Industrial Crops and Products, 28(1), 95-106.

Maizura, M., Fazilah, A., Norziah, M. H. \& Karim, A. A. (2007). Antibacterial activity and mechanical properties of partially hydrolyzed sago starch-alginate edible film containing lemongrass oil. Journal of Food Science, 72(6), C324-C330.

Majdzadeh-Ardakani, K., Navarchian, A. H., \& Sadeghi, F. (2010). Optimization of mechanical properties of thermoplastic starch/clay nanocomposites. Carbohydrate Polymers, 79(3), 547-554.

Mangiacapra, P., Gorrasi, G., Sorrentino, A., \& Vittoria, V. (2006). Biodegradable nanocomposites obtained by ball milling of pectin and montmorillonites. Carbohydrate Polymers, 64(4), 516-523.

Martins, J., Bourbon, A., Pinheiro, A., Souza, B. S., Cerqueira, M., \& Vicente, A. (2013). Biocomposite films based on $\mathrm{\kappa}$-carrageenan/locust bean gum blends and clays: Physical and antimicrobial properties. Food and Bioprocess Technology, 6(8), 2081-2092.

Mathew, A. P., \& Dufresne, A. (2002). Morphological investigation of nanocomposites from sorbitol plasticized starch and tunicin whiskers. Biomacromolecules, 3(3), 609-617.

Mulinacci, N., Ieri, F., Giaccherini, C., Innocenti, M., Andrenelli, L., Canova, G., et al. (2008). Effect of cooking on the anthocyanins, phenolic acids, glycoalkaloids, 
and resistant starch content in two pigmented cultivars of Solanum tuberosum L. Journal of Agricultural and Food Chemistry, 56(24), 11830-11837.

Ojijo, V., \& Sinha Ray, S. (2013). Processing strategies in bionanocomposites. Progress in Polymer Science, 38(10-11), 1543-1589.

Pal, S., Tak, Y. K., \& Song, J. M. (2007). Does the antibacterial activity of silver nanoparticles depend on the shape of the nanoparticle? A study of the gramnegative bacterium Escherichia coli. Applied and Environmental Microbiology, 73(6), 1712-1720.

Ramesh, G. V., Porel, S., \& Radhakrishnan, T. P. (2009). Polymer thin films embedded with in situ grown metal nanoparticles. Chemical Society Reviews, 38(9), 2646-2656.

Raveendran, P., Fu, J., \& Wallen, S. L. (2006). A simple and "green" method for the synthesis of Au, Ag, and Au-Ag alloy nanoparticles. Green Chemistry, 8(1), 34-38.

Reddy, M. M., Vivekanandhan, S., Misra, M., Bhatia, S. K., \& Mohanty, A. K. (2013) Biobased plastics and bionanocomposites: Current status and future opportunities. Progress in Polymer Science, 38(10-11), 1653-1689.

Rhim, J.-W., Hong, S.-I., Park, H.-M., \& Ng, P. K. W. (2006). Preparation and characterization of chitosan-based nanocomposite films with antimicrobial activity. Journal of Agricultural and Food Chemistry, 54(16), 5814-5822.
Shen, X. L., Wu, J. M., Chen, Y., \& Zhao, G. (2010). Antimicrobial and physical properties of sweet potato starch films incorporated with potassium sorbate or chitosan. Food Hydrocolloids, 24(4), 285-290.

Sorrentino, A., Gorrasi, G., \& Vittoria, V. (2007). Potential perspectives of bionanocomposites for food packaging applications. Trends in Food Science $\mathcal{E}$ Technology, 18(2), 84-95.

Sozer, N., \& Kokini, J. L. (2009). Nanotechnology and its applications in the food sector. Trends in Biotechnology, 27(2), 82-89.

Su, J.-F., Huang, Z., Yuan, X.-Y., Wang, X.-Y., \& Li, M. (2010). Structure and properties of carboxymethyl cellulose/soy protein isolate blend edible films crosslinked by Maillard reactions. Carbohydrate Polymers, 79(1), 145-153.

Sun, Q., Li, X., Wang, P., Du, Y., Han, D., Wang, F., et al. (2011). Characterization and evaluation of the Ag+ -loaded soy protein isolate-based bactericidal film-forming dispersion and films. Journal of Food Science, 76(6), E438-E443.

Vogler, E. A. (1998). Structure and reactivity of water at biomaterial surfaces. Advances in Colloid and Interface Science, 74(1-3), 69-117. 